\title{
EDUCAÇÃO AMBIENTAL E O DESCARTE DE RESÍDUOS ELETROELETRÔNICOS NO SUL DE SANTA CATARINA
}

\author{
Rodrigo Rodrigues de Freitas ${ }^{1}$ \\ Vandete Maria Zanatta de Oliveira ${ }^{2}$
}

Resumo: O aumento no consumo de tecnologias e a redução da vida útil dos aparelhos eletrônicos vem gerando aumento nos resíduos, cuja destinação ainda é pouco compreendida pela sociedade, especialmente nos pequenos municípios brasileiros. O objetivo deste trabalho foi analisar, por meio de um questionário, os conhecimentos sobre Resíduos Eletroeletrônicos (REE) e seu descarte por pais de alunos do Ensino Fundamental II de uma escola pública de Urussanga/SC. A maioria dos entrevistados realiza o descarte dos REEs na coleta seletiva do município e desconhecem a legislação específica. São propostas ações de Educação Ambiental para subsidiar estratégias de descarte adequado dos REE por moradores e poder público local.

Palavras-chave: Logística Reversa, Eletrônico, Políticas Públicas, Gestão Ambiental, Urussanga.

Abstract: The increase in the consumption of technologies and the lifespan reduction of electronic devices has generated an increase in waste, whose destination is poorly understood by society, especially in small Brazilian municipalities. The objective of this work was to analyse, through a questionnaire, the knowledge about Electronic Waste (REE) and its disposal by parents of elementary school students from a public school in Urussanga/SC. Most respondents discard REEs in the selective collect of the municipality and are unaware of the specific legislation. Environmental Education actions are proposed to support strategies for the proper disposal of REE by residents and local government.

Keywords: Reverse Logistics, Electronic, Public Policies, Environmental Management, Urussanga.

1 Universidade do Sul de Santa Catarina (Unisul). E-mail: rodrigo.freitas3@unisul.br. Link para o Lattes: http://lattes.cnpq.br/9175936137896864

2 Especialização em Inovação na Educação, Unisul. E-mail: vandetedeoliveira@gmail.com. Link para o Lattes: http://lattes.cnpq.br/2011576302837397 


\section{Introdução}

O aumento no consumo de tecnologias e a redução da vida útil de aparelhos eletrônicos testemunhado nas últimas décadas vem gerando um grande aumento no uso de dispositivos e equipamentos tecnológicos. Sales et al. (2017) relatam que a utilização de Tecnologias de Informação e Comunicação, como computadores pessoais (PCs e notebooks), dispositivos portáteis (smartphones e tablets), impressoras até os dispositivos de comunicação (fibra ótica, cabos de comunicação e equipamentos) aumentaram gradativamente sua produção. Porém, o consistente advento de novos designs, funções inteligentes e tecnologia durante os últimos 20 anos tem causado a rápida obsolescência de muitos itens eletrônicos, uma vez que o tempo de vida dos produtos eletrônicos foi substancialmente reduzido (KIDDEE; NAIDU; WONG, 2013). Segundo Widmer et al. (2005), a média de vida útil de um novo computador diminuiu de 4,5 anos em 1992 para 2 anos em 2005 e há perspectivas de que diminua ainda mais.

Junto com a tecnologia, avança também a geração descontrolada de lixo eletrônico ou, conforme chamaremos no presente artigo, Resíduos Eletroeletrônicos - REE (SALLES et al., 2017). REE é um termo utilizado para designar o material resultante do descarte de equipamentos elétricos e eletrônicos, bem como suas partes e acessórios (BRASIL, 2020c). São exemplos de REE: celulares, computadores, TVs, carregadores, lâmpadas fluorescentes, pilhas, aparelho de DVDs e eletrodomésticos em geral.

O crescimento na produção e utilização dos dispositivos e equipamentos eletrônicos não tem sido acompanhado pelo seu descarte correto. Os REE têm recebido atenção por apresentarem substâncias potencialmente perigosas e pelo aumento em sua geração, que se tornou um problema ambiental, requerendo manejo e controle (BRASIL, 2011).

Conforme Kiddee, Naidu e Wong (2013), o gerenciamento do lixo eletrônico (e-waste) é um dos problemas de poluição que crescem mais rapidamente em todo o mundo. A pesquisa exposta no Plano Nacional de Resíduos Sólidos (BRASIL, 2011) revela que o Brasil produz cerca de 2,6 kg por ano de resíduos eletrônicos por habitante. De acordo com Scharf (2000, p.210), "no Brasil são consumidas por ano, cerca de 910 milhões de pilhas e baterias domésticas". Segundo levantamento da Universidade das Nações Unidas (BRASIL, 2020b), em 2016 foram geradas 45 milhões de toneladas de REE, sendo o valor de matéria-prima estimado em 55 bilhões de euros.

RRE são tóxicos e, se não forem descartados corretamente, causam uma série de danos ao meio ambiente e ao ser humano. Roa (2009) destaca que, dentre as substâncias que compõem as pilhas e baterias, existem os metais pesados, como chumbo, níquel, cádmio, mercúrio, cobre, zinco, manganês, prata, entre outros. Descartados de maneira indevida, estas substâncias podem se infiltrar e contaminar o solo, o lençol freático, a fauna e a flora das regiões próximas, sendo absorvidos pelo ser humano através da cadeia alimentar, podendo provocar doenças que variam de lesões cerebrais a 
disfunções renais e pulmonares. Devido às consequências danosas tanto para a saúde humana quanto para o meio ambiente, o descarte inadequado do lixo eletrônico configura crime ambiental (MACEDO; CAPANO, 2017).

Além de evitar danos, a reciclagem de REE permite que a matériaprima contida nos aparelhos seja recuperada, tratada e reaproveitada em novos produtos. Segundo Sales et al. (2017), concomitantemente ao potencial nocivo, os REE também oferecem oportunidades de inovação e criação de novos produtos, minimizando, assim, o impacto ambiental. A reutilização e reciclagem desses dispositivos eletrônicos podem gerar tanto ganhos financeiros, como evitar que materiais tóxicos sejam lançados no meio ambiente.

O conjunto de ações, procedimentos e meios destinados a viabilizar a coleta e a restituição dos resíduos sólidos ao setor empresarial para reaproveitamento ou outra destinação final ambientalmente adequada é chamada de Logística Reversa (Brasil, 2010). Porém, parte da população não dispõe de informações sobre os perigos causados ao solo e à saúde humana ocasionados pelo descarte incorreto do lixo eletrônico, o que permite aos fabricantes protelarem a adoção de medidas para amenizar os impactos ambientais (ROA, 2009). O referido artigo relata que 58\% da população do município de Frederico Westphalen/RS, compra pilhas comuns por serem mais baratas, porém seus componentes são mais poluentes que as pilhas alcalinas. Ainda, $82 \%$ da população descarta as pilhas em lixos comuns e apenas $18 \%$ buscam um descarte correto (ROA, 2009).

A despeito das regulamentações existentes, o processo de adequação do descarte de REE em muitos municípios brasileiros ainda se encontra nos estágios iniciais. A falta de estrutura na coleta e as poucas empresas na área de reciclagem, representam um problema para a destinação de REE. Esta é a situação do município de Urussanga/SC, que não realiza o descarte correto dos REE, seja pela falta de conhecimento dos malefícios do descarte indevido, seja pela falta de informação acerca dos pontos de coleta.

Desta forma, destaca-se a importância da Educação Ambiental (EA), que busca a construção de valores sociais, conhecimentos, habilidades, atitudes e competências, individuais e coletivas, voltadas para a conservação do meio ambiente. O ambiente escolar, neste artigo, é percebido como um importante local de construção e propagação do conhecimento (BRASIL, 1999).

Através de uma pesquisa descritiva e quali-quantitativa realizada com os familiares de alunos da Escola Estadual de Educação Básica Caetano Bez Batti, de Urussanga-SC, buscou-se responder às seguintes perguntas de pesquisa: Como é realizado o descarte do REE pelas famílias do município? A população tem conhecimento dos malefícios dos REE para o ambiente e para saúde humana? Ocorre a devolução dos REE às lojas, conforme as orientações federais? Através deste recorte da realidade do município, os resultados da pesquisa poderão ser ampliados para subsidiar 0 
desenvolvimento de ações no âmbito municipal, como materiais informativos e práticas de EA sobre o descarte do REE, incluindo informações sobre os materiais que compõem os REE, quais as condutas adequadas para o seu descarte e encaminhamento para a reciclagem.

O presente artigo traz inicialmente uma revisão da legislação sobre o tema, um breve referencial teórico acerca da Educação Ambiental, o contexto da área de estudo e os métodos de coleta e análise de dados. Posteriormente, são apresentados os resultados da pesquisa realizada no município de Urussanga/SC. A discussão aborda a urgência da temática e as possibilidades de ampliar o debate conjugando políticas públicas e práticas de EA relacionadas a coleta dos REE.

\section{Legislação sobre REE}

Diante da grande produção de REE, o Conselho Nacional do Meio Ambiente - CONAMA, aprovou em 30 de junho de 1999 a Resolução CONAMA $n^{\circ} 276$, que "estabelece a obrigatoriedade de procedimentos de reutilização, reciclagem, tratamento ou disposição final ambientalmente adequada para pilhas e baterias que contenham em suas composições chumbo, cádmio, mercúrio e seus compostos" (BRASIL, 1999b, p.1).

Em 2009, foi criada pelo CONAMA a Resolução 401 (BRASIL, 2009), alterada pela Resolução no 424, de 2010, a qual preconiza que os pontos de vendas de pilhas e baterias precisam disponibilizar aos consumidores pontos de coleta e o devido encaminhamento para os fabricantes, que serão responsáveis pela reciclagem (Brasil, 2010a). Se isso não for possível, esse descarte deverá ser feito em aterros sanitários licenciados.

Em 2010, foi instituída a Política Nacional de Resíduos Sólidos - PNRS - Lei no 12.305/2010 que, regulamentada pelo Decreto no 7.404 de 2010, criou como um dos seus principais instrumentos o Plano Nacional de Resíduos Sólidos (BRASIL, 2010b). Em seu artigo 3o, a Lei prevê a implantação da Logística Reversa: "um conjunto de ações, procedimentos e meios destinados a viabilizar a coleta e a restituição dos resíduos sólidos ao setor empresarial, para reaproveitamento, em seu ciclo ou em outros ciclos produtivos, ou outra destinação final ambientalmente adequada" (BRASIL, 2010b, p.1). Este Plano apresentou um diagnóstico de alguns dos resíduos definidos como objetos obrigatórios da logística reversa e buscou subsidiar o planejamento de ações que possam promover o desenvolvimento socioeconômico e preservar a qualidade ambiental para os resíduos objetos da Logística Reversa prevista na Lei 12.305/2010 e nos Decretos 7.404/2010 e 9.177/2017 (BRASIL, 2011).

Em setembro de 2015, o Brasil assumiu o compromisso de implementar a Agenda 2030 para o Desenvolvimento Sustentável. Os Objetivos de Desenvolvimento Sustentável (ODS) fazem parte de uma resolução internacional aprovada pela Assembleia Geral da Organização das Nações Unidas (ONU). Essa define uma estratégia mundial composta por 17 objetivos

revista brasileira educação ambiental 
e 169 metas, orientando para planejamento de ações e políticas públicas perenes, capazes de levar o Brasil ao efetivo alcance do desenvolvimento sustentável.

Dentre os objetivos, destacamos a ODS 12, que aborda a produção e o consumo sustentáveis, com foco em ações globais e locais, como: alcançar o uso eficiente de recursos naturais (12.2), manejar resíduos químicos de maneira responsável e diminuir emissão de poluentes (12.4), reduzir a geração de resíduos por meio da prevenção, redução, reciclagem e reutilização (12.5) e garantir que as pessoas tenham informação relevante e conscientização para o desenvolvimento sustentável e estilos de vida em harmonia com a natureza (12.8) (BRASIL, 2019).

Em 12 de fevereiro de 2020, foi assinado o Decreto 10.240, que regulamenta a logística reversa de produtos eletroeletrônicos, obrigando as empresas do setor a implantarem sistemas de coleta desse tipo de resíduo e dar sua destinação correta. No Capítulo XIV, Art.49 relata que a estruturação e a implementação do sistema de logística reversa ocorrerá no prazo de cinco anos a contar da data de publicação (BRASIL, 2020). Dividida em duas fases, a primeira trata da estruturação e regulamentação dos órgãos e produtos eletroeletrônicos. A segunda fase, que tem início em janeiro de 2021 até dezembro de 2025, compreende a habilitação de prestadores de serviços que poderão atuar no sistema de logística reversa de produtos eletroeletrônicos, a elaboração de planos de comunicação e de EA não formal, e a instalação de pontos de recebimento ou de consolidação, de acordo com cronograma disposto no próprio decreto.

Segundo reportagem da Agência Brasil, existem atualmente 173 pontos de coletas de REEs no território nacional, e que, com esta regulamentação, prevê que aumente para 5 mil pontos até 2025 (VILELA, 2020). Segundo Brasil (2011), para a implementação da logística reversa é necessário um acordo setorial mediado pelo poder público, fabricantes, importadores, distribuidores ou comerciantes para que haja a implementação da responsabilidade compartilhada. Conjuntamente, faz-se necessário o conhecimento da realidade e o planejamento das metas e ações.

\section{A Educação Ambiental como meio para alcançar o Desenvolvimento Sustentável}

A PNRS estabelece a necessidade de sensibilização dos vários segmentos da sociedade, inclusive dos profissionais da área e a população como um todo, para que suas metas sejam alcançadas. Em seu art. $2^{\circ}$, inciso IV, atribui o papel de sensibilização e mobilização sobre a destinação dos resíduos à Educação Ambiental - EA (BRASIL, 2011).

Segundo a Lei 9.795 (Política Nacional de Educação Ambiental), estabelecida em 27 de abril de 1999, a EA é considerada como "(...) o processo por meio do qual o indivíduo e a coletividade constroem valores sociais, conhecimentos, habilidades, atitudes e competências voltadas para a 
conservação do meio ambiente, bem de uso comum do povo, essencial à sadia qualidade de vida e sua sustentabilidade". A lei citada acima, no seu Art. 2ํㅡ, expõe o conceito da Educação Ambiental como “(...) um componente essencial e permanente da educação nacional, devendo estar presente, de forma articulada, em todos os níveis e modalidades do processo educativo, em caráter formal e não-formal” (BRASIL, 1999a).

Em estudo realizado por Otero; Neiman (2015), os autores analisaram os avanços e desafios da Educação Ambiental brasileira entre a Rio 92 e a Rio+20. Percebeu-se que a partir de 92, emergiram várias práticas sociais e políticas a favor do desenvolvimento da Educação Ambiental. Observou-se que, após os 20 anos de reformulação, a EA influenciou o pensamento e a vida dos brasileiros, e que de uma forma geral, o sistema de cultura, economia, sustentação e reprodução voltada para o meio ambiente foram realizados. Práticas que no âmbito educacional influenciou diretamente para superação dos cidadãos enquanto agentes transformadores da sociedade. Desta forma, a EA foi percebida enquanto uma prática de transformação, no combate à crise ambiental iminente.

De acordo com Carvalho (2013), os valores ecológicos de cuidado, responsabilidade e solidariedade com o ambiente é um processo formativo, relacionado ao desenvolvimento da subjetividade do ser. A educação é, em todas as suas modalidades, uma prática formativa, e a escola é o espaço institucional onde esta formação transcorre de forma planejada e intencional na sociedade moderna. Ela é permeada por relações institucionais, locais, raciais, comunitárias, políticas, o que faz da vida escolar um espaço significativo de formação do sujeito, possibilitando a formação do "sujeito ecológico". Ressalta, ainda que esta dimensão "ecológica" pode ser assumida não só por indivíduos, mas também grupos e instituições como a escola ou as políticas públicas, e que a identificação dos valores ecológicos deve ser desenvolvida dentro e fora da escola.

Independente da metodologia utilizada, a escola deve promover experiências e possibilitar a provocação do pensamento crítico sobre os muitos modos possíveis - os existentes, os ecologicamente desejáveis e os não ecológicos - de habitar, viver e conviver no mundo desde uma perspectiva social e ambientalmente responsável (CARVALHO, 2013)

Através de uma revisão de literatura, Silva; Santos e Jesus (2018), reforçam a necessidade de institucionalização de uma política ambiental no ensino, desde o básico até o universitário, para renovar a esperança de uma geração futura consciente e responsável perante o maior bem da humanidade: o meio ambiente. Os autores destacam a inserção da EA nas escolas, sendo necessários mais estudos relacionados ao tema e a efetivação da implantação da EA em todos os níveis de ensino.

A seguir serão apresentados os resultados do questionário que analisou o conhecimento de uma parcela da população de Urussanga sobre os REE e sua destinação. 


\section{Área de estudo: O descarte do REE no município de Urussanga, SC}

A pesquisa foi realizada na cidade de Urussanga, localizada no Extremo Sul Catarinense, situada a $185 \mathrm{Km}$ da capital Florianópolis. Possui uma área territorial de 254,869 Km2, sendo banhada pela Bacia Hidrográfica do Rio Urussanga, com vegetação formada principalmente pela Floresta Ombrófila Densa Montana, incluindo áreas de reflorestamento com eucaliptos. Sua população é estimada em 21.344 habitantes e o IDHM (Indice de Desenvolvimento Humano Municipal) é de 0,772. A economia do município é mista, baseada em indústrias, dentre elas destaca-se a de artigos plásticos, cerâmicas, esquadrias de alumínio e vitinicultura (IBGE, 2020)

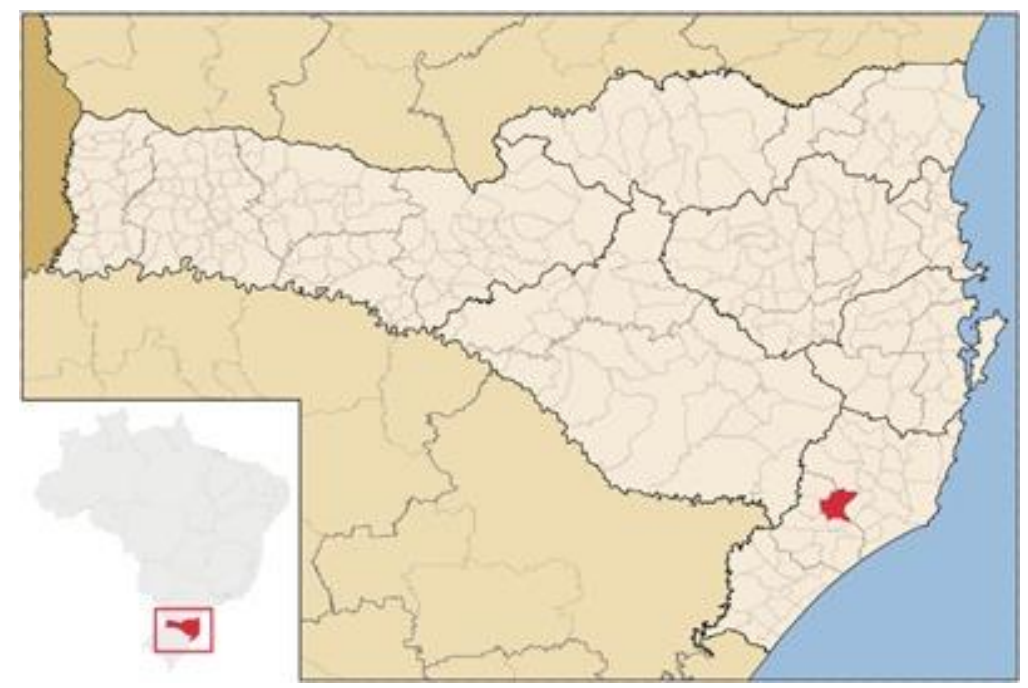

Figura 1: Mapa geográfico do Estado de Santa Catarina com destaque para o município de Urussanga. Fonte: Abreu (2006).

A Prefeitura de Urussanga realiza apenas coleta de lixo domiciliar (PREFEITURA, 2015), sendo a coleta seletiva realizada desde 2008 pelo Consórcio Intermunicipal de Resíduos Sólidos Urbanos da Região Sul (CIRSURES) e apoia atividades de reciclagem, em conjunto com a Cooperamérica (Cooperativa de catadores do Rio América). O CIRSURES foi criado no ano de 2001, sendo composto atualmente por sete municípios. O CIRSURES informa à população que os REE devem ser devolvidos no local de compra (RESÍDUOS ESPECIAIS, 2020), porém, o desconhecimento desta orientação pela maioria da população de Urussanga incentivou esta pesquisa.

O diagnóstico obtido através do Plano Nacional de Resíduos Sólidos (BRASIL, 2011) deixa clara a importância do investimento em um Plano de Comunicação e de Educação Ambiental com estratégias e novas linguagens capazes de ampliar as possibilidades de envolvimento, sensibilização e mobilização da sociedade, estimulando a reflexão sobre a cultura do desperdício e o atual padrão de produção e consumo, bem como, sobre qualidade do ambiente urbano, cuidado dos recursos naturais e respeito à vida. 


\section{Métodos de coleta e análise dos dados}

A coleta de dados primários foi realizada por meio da aplicação de um questionário, sendo utilizada uma plataforma digital (Google Forms) para o preenchimento dos dados pelos participantes da pesquisa. A população do estudo foi composta pelos pais/responsáveis dos alunos dos Anos Finais do Ensino Fundamental da Escola Estadual de Educação Básica Caetano Bez Batti, de Urussanga/SC, representando as famílias da comunidade escolar.

O questionário foi composto por perguntas fechadas, de múltipla escolha, com categorias definidas à priori, sobre: (i) identificação pessoal (idade, grau de escolarização e bairro de domicílio); (ii) conhecimento acerca de REE; (iii) importância da separação do lixo; (iv) conhecimento acerca da realidade do município quanto à coleta seletiva e coleta de REE; (v) identificação dos materiais que fazem parte dos REEs e encaminhamento dado pela família a estes materiais e; (vi) conhecimento acerca da legislação. Adicionalmente, continha duas perguntas abertas, possibilitando sugestões para o poder público quanto ao descarte de REE e comentários gerais sobre a pesquisa.

O questionário foi disponibilizado às famílias de 256 alunos, do $6^{\circ}$ ao $9^{\circ}$ ano escolar. Em virtude da Pandemia do Covid-19, as turmas da unidade escolar possuem grupos de WhatsApp, e o link do questionário para participação da pesquisa foi encaminhado a um grupo de pais administrado pela direção escolar. O questionário foi disponibilizado no período de 14 a 25 de outubro de 2020, sendo orientado que cada família respondesse apenas um questionário, totalizando 43 respostas.

Os dados coletados pela plataforma digital foram organizados na planilha eletrônica do Microsoft Excel. Para organização dos resultados foi utilizada estatística descritiva, com cálculo da frequência relativa das respostas e organização gráfica para melhor visualização das informações.

\section{Resultados}

O maior percentual dos entrevistados esteve na faixa etária entre 31-40 anos $(53,5 \%)$, seguido da faixa etária de $41-50$ anos $(30,2 \%)$. No restante, $11,6 \%$ apresentam 51 anos ou mais, e 4,7\% encontra-se na faixa etária até 30 anos de idade. Quanto ao grau de escolaridade, 34,9\% possuíam Ensino Superior, 41,9\% o Ensino Médio, 18,6\% o Ensino Fundamental e 4,6\% não concluíram o Ensino Fundamental. Os participantes residiam em treze bairros do município, sendo o principal bairro "Estação" (37,2\%), local onde a escola está instalada, seguidos dos bairros vizinhos "Bela Vista" (18,6\%) e "Centro" $(9,3 \%)$; o Loteamento Carol, Bairro De Villa, Nova Itália, Bom Jesus e Rio Caeté tiveram 4,6\% cada; por fim, os bairros Bel Recanto, Morro da Glória, Santana, Rio Carvalho e Águas Mornas responderam por 2,3\% cada um.

revista brasileira educação ambiental 
Quase totalidade dos entrevistados $(97,7 \%)$ considera importante a separação dos diferentes tipos de lixo (Figura 2). Todas as respostas sobre separação do lixo informam que a prática é importante ao meio ambiente, sendo o combate à poluição $(53,5 \%)$ a principal justificativa atribuída.

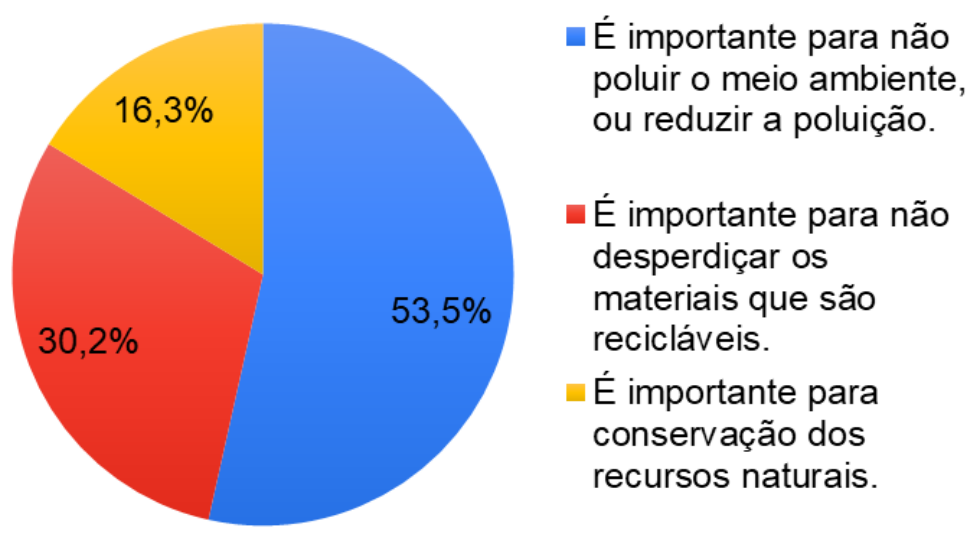

Figura 2: Importância da separação do Lixo.

Fonte: autoria própria.

No questionamento sobre a existência da coleta seletiva de lixo na cidade, 97,7\% afirmaram conhecer o serviço (Figura 3). O mesmo percentual fora encontrado no questionamento quanto ao conhecimento do termo REE, onde responderam que é formado por materiais eletrônicos como televisores, computadores, celulares, dentre outros.

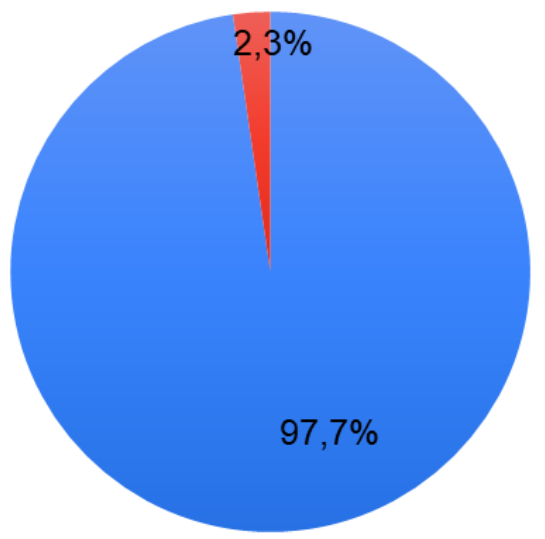

\author{
- Entendo que é formado por \\ materiais eletrônicos como TV, \\ computadores, celulares, dentre \\ outros. \\ - Já ouvi falar, mas não sei \\ exatamente do que se trata. \\ Nenhum. É a primeira vez que \\ vejo este termo
}

Figura 3: Conhecimento do termo Resíduo Eletroeletrônico.

Fonte: autoria própria.

A verificação acerca do entendimento sobre os equipamentos e materiais que compõe os REE foi realizada por meio da indicação dos itens que consideravam parte deste grupo (Figura 4). As respostas evidenciam o 
conhecimento de aparelhos eletrônicos como sendo os principais componentes, porém, relógios e carrinhos de fricção foram citados, sendo que estes equipamentos não compõem os REE, apenas a pilha utilizada.

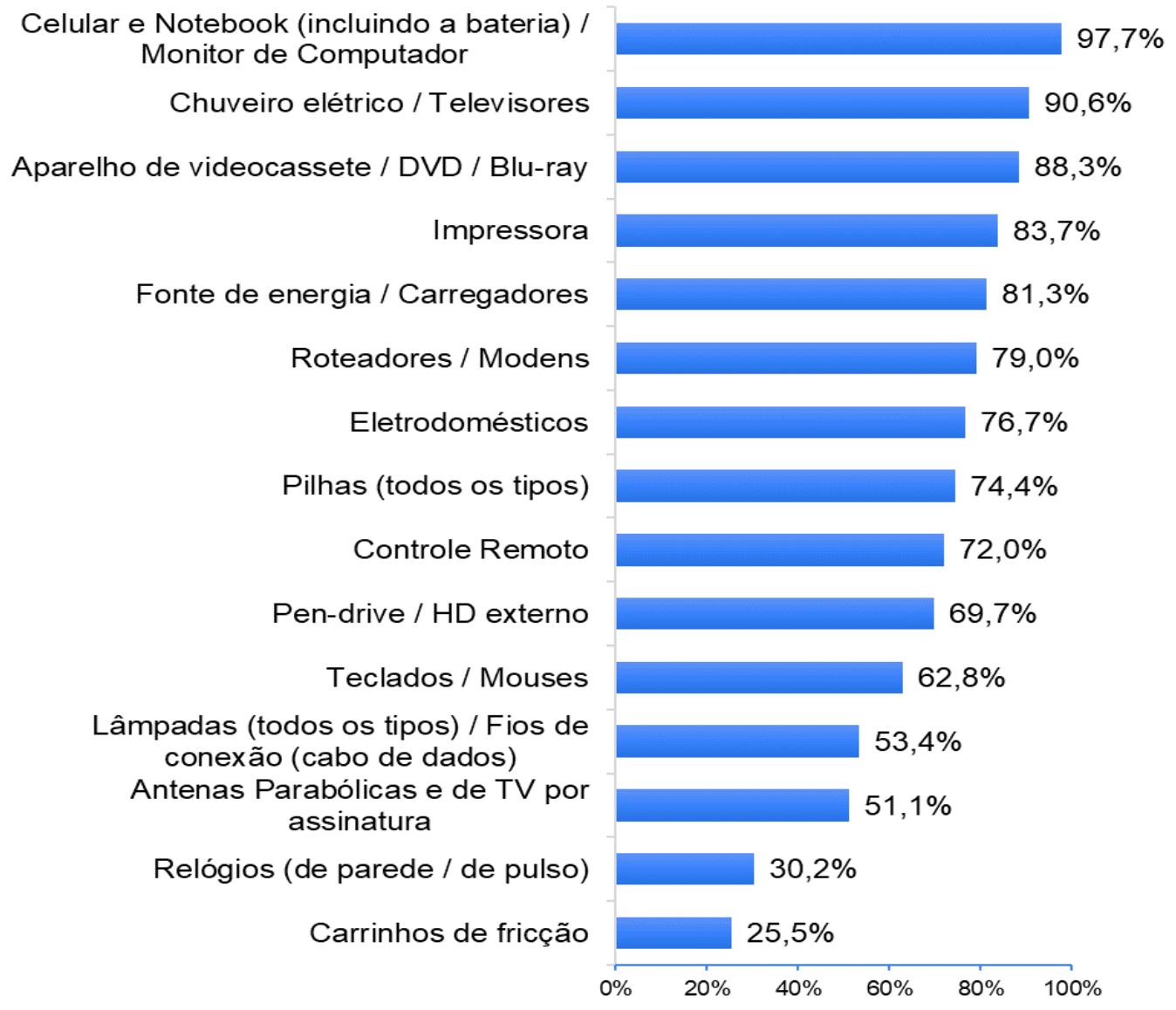

Figura 4: Opinião sobre quais os equipamentos e materiais compõe os REEs.

Fonte: autoria própria.

A Figura 4 transmite a realidade sobre o déficit de compreensão a respeito dos materiais que formam os REEs. Também foram levantadas informações quanto à produção de REE (Figura 5). O questionamento quanto a substituição destes equipamentos apontou que pilhas e lâmpadas são os materiais que mais produzem REE. Destacamos também a constante troca de celulares, chuveiros elétricos e eletrodomésticos. 


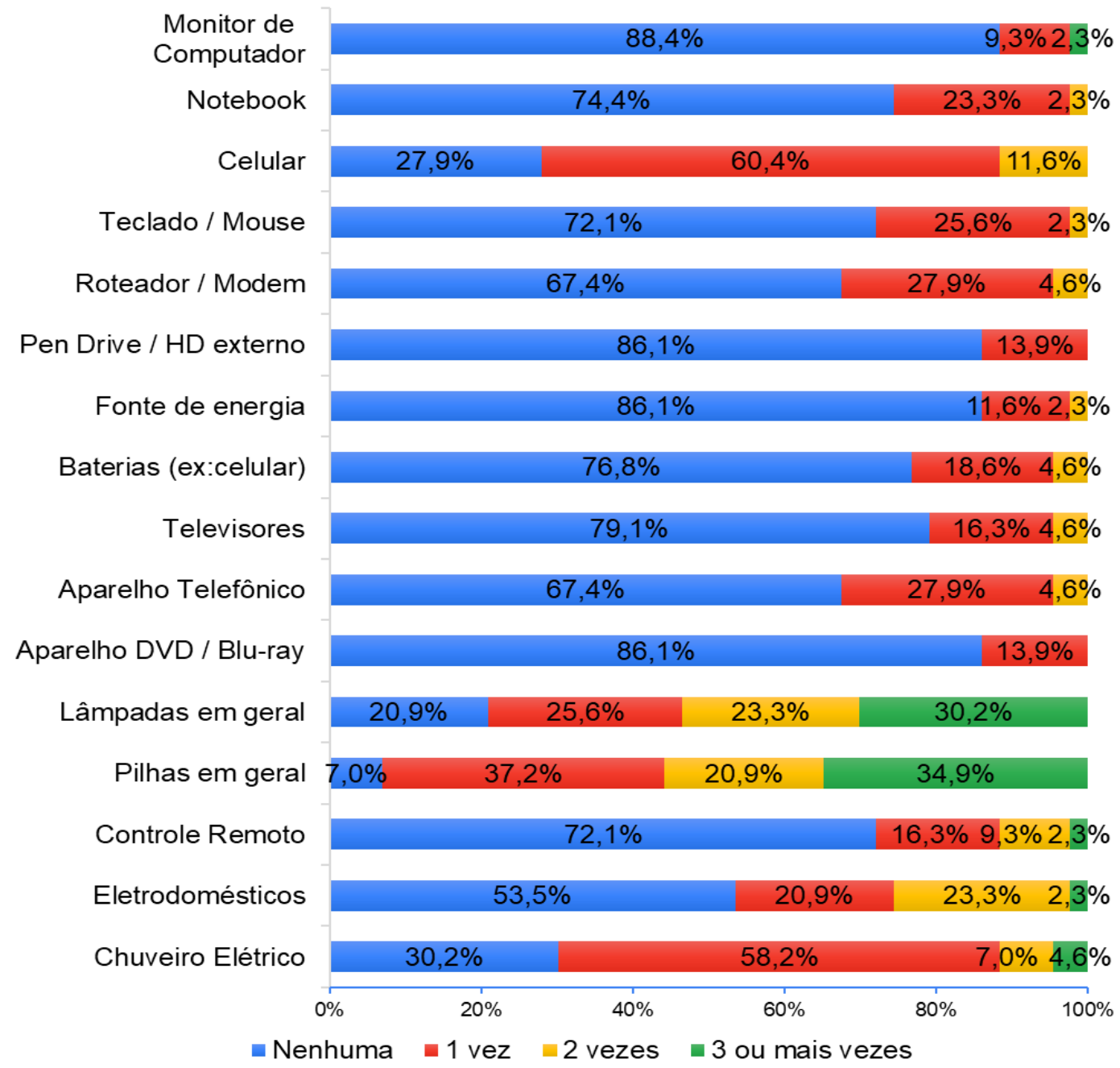

Figura 5: Frequência de troca dos aparelhos eletroeletrônicos nos últimos 2 anos.

Fonte: autoria própria.

Dentre os REEs identificados pelas famílias, o direcionamento mais comum dado a estes materiais é o descarte na coleta seletiva municipal (27,9\%), enquanto $11,6 \%$ realiza o descarte no lixo comum. O descarte em campanhas de recolhimento de REE é realizado por $25,6 \%$ dos entrevistados, enquanto $11,6 \%$ declarou realizar a entrega destes equipamentos no comércio local (Figura 6). 


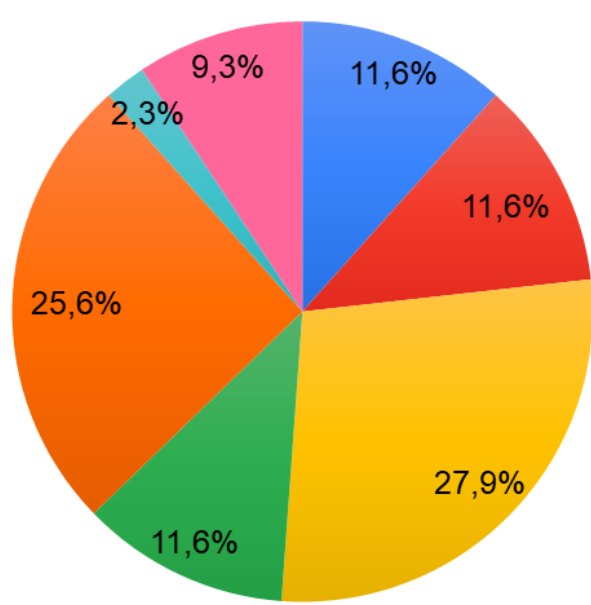

- Não descartei, está guardado em casa.

- Descartei no lixo comum (inteiro ou em pedaços).

Descartei no caminhão da coleta seletiva.

- Entreguei no local de compra do equipamento ou assistência técnica.

- Descartei em campanhas de coleta de materiais eletrônicos.

Figura 6: Formas de descarte dos Resíduos Eletroeletrônicos.

Fonte: autoria própria.

A atitude adequada observada confronta com os $76,8 \%$ dos entrevistados que desconhecem se o município possui local para coleta de REE permanentemente (Figura 7). Aliado a este fato, 93\% dos participantes desconhecem a existencia de legislação específica sobre REE.

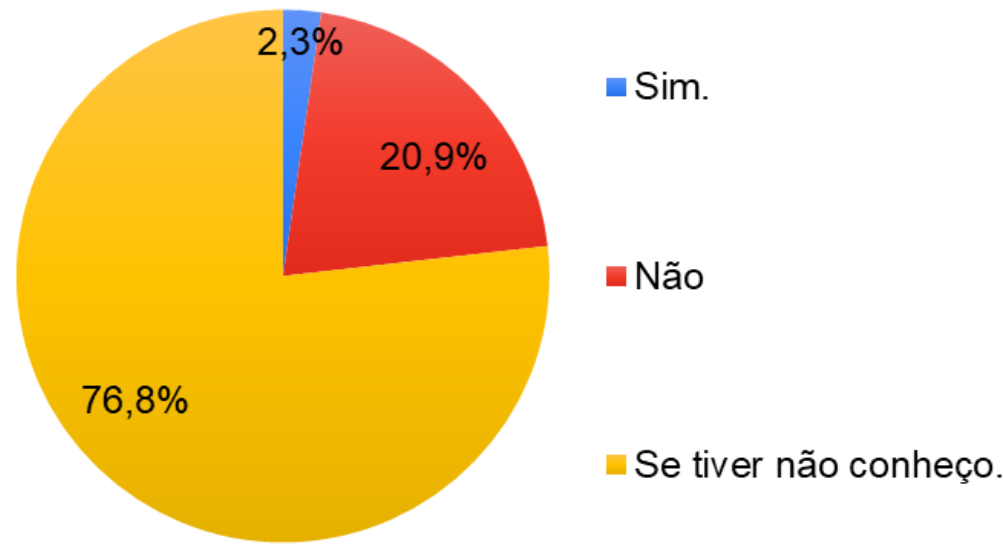

Figura 7: Conhecimento sobre locais de coleta de Resíduos Eletroeletrônicos.

Fonte: autoria própria.

Corrobora com os dados já apresentados referente ao cuidado com os REEs, $86 \%$ dos participantes informaram que levariam com certeza, os materiais a um comércio ou escola que promovessem o destino adequado, caso estes locais existissem no município.

As sugestões para ações no município $(n=32)$ incluíram a organização de postos de arrecadação (62,5\%), campanhas de conscientização $(31,2 \%)$ e 
divulgação destes locais de coleta (18,8\%). Destacamos algumas das sugestões apresentadas:

"As escolas do município arrecadam pilhas e baterias de celulares ou de brinquedos, como uma forma de conscientizar o descarte correto. Esse tipo de ação poderia ser mais divulgado e mais abrangente coletando outros tipos de eletrônicos" (Participante A).

“(...) falta consciência das pessoas, e também mais pressão dos governantes sobre todas as cidades ter coletas mais assíduas" (Participante B).

"Há necessidade de olhar mais objetivo e profundo para as fontes domésticas de materiais nocivos, poluidores, contaminadores em potencial como a radioatividade das pilhas e baterias, os aerossóis, os componentes de amianto ainda muito comuns (...), a comunidade deveria ter conhecimento sobre o estrago causado por estes materiais (...) e criar uma central de recolhimento desses materiais com urgência, e também análises laboratoriais permanentes do local de descarte" (Participante C).

"O descarte de resíduos eletrônicos merece uma atenção especial do poder público e dos órgãos ambientais fiscalizadores, devido ao aumento do consumo das pessoas de produtos eletrônicos. Com a globalização, e as diversas inovações tecnológicas, cada vez mais o público consumidor tem substituídos seus aparelhos eletrônicos pelas novidades do mercado, e em muitos casos não há um correto destino ao produto eletrônico que ficou obsoleto, sendo muitas vezes descartados de forma aleatória, seja no lixo residencial, seja em outros pontos não apropriados. É importante a conscientização da população deste assunto e dos cuidados com o descarte de resíduos eletrônicos, bem como, os demais resíduos comuns a sociedade" (Participante D).

\section{Discussão}

O Relatório da Organização das Nações Unidas (ONU, 2015) traz o Brasil como o maior produtor de resíduo eletrônico da América Latina em 2014 e $07^{\circ}$ do mundo. Estima-se que o mundo deva produzir 50 milhões de toneladas de REE em 2020, e menos de $20 \%$ deste lixo é reciclado de maneira correta (BRASIL, 2020b). O restante, ou seja, $80 \%$ do REE produzido, é descartado em aterros ou são informalmente reciclados, podendo trazer malefícios as pessoas que ali trabalham.

Os problemas relacionados aos REE iniciam pelo desconhecimento geral de quais os materiais fazem parte deste grupo. Segundo Baldé et al. (2017) os REEs são agrupados em: (i) Equipamentos de refrigeração / aquecimentos: geladeiras, freezer, etc.; (ii) Monitores e telas de televisão; (iii) Equipamentos de grande porte: fogões elétricos, copiadoras, painéis 
fotovoltaicos, etc.; (iv) Equipamentos de pequeno porte: forno de micro-ondas, secadores de cabelo, rádios, dentre outros e; (v) Equipamentos de TI como telefones celulares. Lâmpadas (incluindo fluorescentes e LED) pilhas e baterias são também REE, mas fazem parte de um sistema de logística reversa já especificado na Resolução Conama 401/2009 e Lei 12.305/2010, não estando inclusas no Decreto 10.240/2020.

Pilhas e lâmpadas são os itens mais citados pelos entrevistados em termos de quantidade de trocas e frequência de descarte. Pesquisa realizada pela Associação Brasileira da Industria Elétrica e Eletrônica - ABINEE (ROA, 2009), demonstra que no Brasil são produzidos, ao ano, cerca de três bilhões de pilhas e baterias domésticas. Quando despejados no lixo, junto a resíduos sólidos comuns, as substâncias contidas podem contaminar o solo, os lençóis freáticos, a fauna e a flora de regiões próximas. Cada bateria ou pilha descartada incorretamente, contamina uma área de um metro quadrado; se absorvidos pelo ser humano, podem provocar doenças que variam de lesões cerebrais a disfunções renais e pulmonares (ROA, 2009).

Em Urussanga, 27,9\% dos participantes informaram que materiais como celulares, baterias e componentes de computador são descartados junto à coleta seletiva de materiais recicláveis existente no município. A Engenheira Ambiental responsável pela coleta seletiva do Cirsures esclarece que a empresa não está autorizada a realizar a coleta dos REE, visto que os mesmos são enquadrados na Logística Reversa; ao passar estes materiais pela esteira do centro de triagem, os cooperados separam os REE, desmontam para aproveitar as partes recicláveis e descartam para o aterro o que não é aproveitável, independente do potencial poluidor.

Apesar de $25,6 \%$ dos entrevistados informarem ter descartado os REE em campanhas de coleta realizadas no município, em Urussanga não existem postos de coleta de REE e as campanhas de coleta de material eletroeletrônico não ocorrem com frequência. A Fundação Ambiental Municipal de Urussanga (FAMU) informou que a única campanha de coleta de REE foi realizada no ano de 2019. Os REE coletados foram entregues a uma empresa que faz recolhimento deste material. Informaram ainda que não há atualmente nenhum projeto específico para os REE no município.

A mesma porcentagem $(25,6 \%)$, relata ter devolvido o material nos locais de compra, mas não se tem informações sobre o destino que estes locais dão aos resíduos. Quando não descartado junto à coleta seletiva ou em raras campanhas existentes, grande parte dos REE de Urussanga são descartados junto ao lixo comum, contaminando o aterro sanitário, lençóis freáticos e, consequentemente, a população do município. Segundo Roa (2009), o desconhecimento dos malefícios do descarte incorreto permite aos fabricantes protelarem a adoção de medidas para amenizar os impactos ambientais.

Há um desconhecimento geral da população acerca da legislação, representada por $93 \%$ dos entrevistados. Mesmo quem afirma conhecer, não

revista brasileira educação ambiental 
pode citar nenhuma das regulamentações existentes. Segundo o Decreto 10.240/2020, os consumidores devem entregar seu REE a loja onde adquiriu o produto. Cabe aos comerciantes receber, acondicionar e armazenar os produtos eletroeletrônicos descartados pelos consumidores e efetuar a devolução aos fabricantes e aos importadores. Os distribuidores devem incentivar a adesão às entidades gestoras, informar aos estabelecimentos varejistas a operacionalização do sistema, disponibilizar ou custear espaços físicos para os pontos de consolidação. Cabe aos fabricantes e importadores dos artigos eletroeletrônicos dar a destinação final ambientalmente adequada, preferencialmente para reciclagem de $100 \%$ dos produtos recebidos pelo sistema (BRASIL, 2020.)

Para que as diretrizes da PNRS sejam cumpridas e suas metas alcançadas, é necessária a sensibilização dos vários segmentos da sociedade, inclusive dos profissionais da área e a população como um todo (BRASIL, 2011). O Art. $2^{\circ}$, inciso IV da PNRS atribui o papel de sensibilização e mobilização sobre a destinação dos resíduos à EA.

Um dos lugares mais importantes e eficientes para a se implementar a EA é o ambiente escolar. A Política Nacional de Educação Ambiental - PNEA, define que as atividades de EA na escola devem abarcar: capacitação de recursos humanos; desenvolvimento de estudos, pesquisas e experimentos; produção e divulgação de material educativo; acompanhamento e avaliação das atividades educativas e do aprendizado (BARBIERI; SILVA, 2011)

A problemática dos REE, de acordo com os artigos 10 e 11 da PNEA (BRASIL, 1999a) deve constar no currículo das disciplinas, numa perspectiva transdisciplinar. A transdisciplinaridade, conforme orienta Nicolescu (1999), diz respeito àquilo que está ao mesmo tempo entre as disciplinas, através das diferentes disciplinas e além de qualquer disciplina, sendo seu objetivo a compreensão do mundo presente, para o qual um dos imperativos é a unidade do conhecimento. Kitajima et al (2019) sugere algumas aplicações da problemática dos REE na educação:

- Matemática: quantificação de materiais e insumos;

- Física: envolvendo eletricidade;

- Química: composição química do REE e dos materiais tóxicos;

- Biologia: efeitos que os componentes tóxicos podem causar nos seres vivos;

- Organização Social e política (ou disciplinas similares): legislação existente sobre os REE.

\section{Conclusões}

Nosso planeta está se tornando um grande depósito de REE em virtude da crescente produção e consumo das inovações tecnológicas, da redução no ciclo de vida dos equipamentos, da facilidade na aquisição, mas, principalmente, pela falta de conscientização relacionados ao seu descarte, bem como, a falta de políticas públicas que amenizem esse impacto na 
natureza. A toxidade na composição destes equipamentos, quando descartados de forma inadequada, causam problemas ambientais e ao ser humano.

Nossos resultados demonstram o quanto se faz necessário campanhas de conscientização acerca dos REEs, elencar a nocividade de seus componentes, dos malefícios que o descarte incorreto ocasiona ao ambiente e a si próprio, bem como, o conhecimento acerca da legislação como forma de cobrar dos produtores e governantes sua aplicação.

A EA é um ponto de partida e demonstra ser um instrumento eficiente para mitigar problemas ambientais, devendo ser abordada em todos os setores da sociedade, e em todas as fases da vida. Aplicada no ambiente escolar, possibilita aos estudantes uma formação crítica, propagação do conhecimento e, consequentemente, uma mudança social.

Com o intuito de dar início à implantação da EA na E.E.B. Caetano Bez Batti, de Urussanga-SC, os resultados desta pesquisa serão divulgados à comunidade escolar, e poderão ser utilizados como base para a produção de material educativo, atingindo os estudantes, seu familiares e comunidade em geral. Além disso, há um potencial também da pesquisa influenciar as políticas públicas municipais. A FAMU, por exemplo, solicitou retorno dos resultados da pesquisa, demonstrando interesse na temática. Este processo demonstra 0 potencial de iniciativas simples e pouco pretensiosas de EA em ganhar escala e influenciar níveis mais amplos da sociedade.

\section{Agradecimentos}

Agradecemos ao Programa de Bolsas Universitárias de Santa Catarina (UNIEDU) por financiar esta pesquisa junto ao curso de pós-graduação em Inovação na Educação da Universidade do Sul de Santa Catarina (UNISUL). Somos gratos à Direção da Escola Educação Básica Caetano Bez Batti, aos estudantes e seus familiares participantes.

\section{Referências}

ABREU, R.L. Localização de Urussanga. Wikipédia: Urussanga. 2006. Disponível em <https://pt.wikipedia.org/wiki/Urussanga>. Acesso em: 12 set. 2020.

BALDÉ, C.P.; FORTI V.; GRAY, V.; KUEHR, R.; TEGMANN, P. The Global eWaste Monitor - 2017. United Nations University, International Telecommunication Union (ITU) \& International Solid Waste Association (ISWA), Bonn/Geneva/Vienna, 2017. Disponível em < https://www.itu.int/en/ITU-D/Climate-change/Documents/GEM\%202017/GlobalE-waste\%20Monitor\%202017\%20.pdf> Acesso em: 02 març. 2021.

BARBIERI, J.C.; SILVA, D. Educação Ambiental na Formação do Administrador. São Paulo: Cengage Learning, 2011.

revista brasileira educação ambiental 
BRASIL. Lei 9.795 de 27 de abril de 1999. Institui a Política Nacional de Educação Ambiental, 1999. Disponível em: $<$ thtp://www.planalto.gov.br/ccivil 03/leis/19795.htm>. Acesso em: 05 jul. 2020.

BRASIL, Ministério do Meio Ambiente. Resolução CONAMA no 257, de 30 de junho de 1999.1 Disponível em: $<$ https://www.mma.gov.br/estruturas/a3p/ arquivos/36 09102008040356.pdf >. Acesso em: 04 jul. 2020.

BRASIL, Ministério do Meio Ambiente. Resolução CONAMA no 401, de 04 de novembro de 2009.2 Disponível em: $<$ http://www2.mma.gov.br/port/conama/legiabre.cfm?codlegi=589>. Acesso em: 05 jul. 2020.

BRASIL, Ministério do Meio Ambiente. Resolução CONAMA no 424, de 22 de abril de 2010. Disponível em: $<$ http://www2.mma.gov.br/port/conama/legiabre.cfm?codlegi=629>. Acesso em: 05 jul. 2020.

BRASIL. Lei n.12.305 de 12 de agosto de 2010. Institui a Política Nacional de Resíduos Sólidos; altera a Lei no 9.605, de 12 de fevereiro de 1998; e dá outras providências. $2010 . \quad$ Disponível em <http://www.planalto.gov.br/ccivil 03/ ato2007-2010/2010/lei/l12305.htm>.

Acesso em: 04 jul. 2020.

BRASIL, Ministério do Meio Ambiente. Plano Nacional de Resíduos Sólidos. Brasília, set. 2011. Disponível em: $<$ https://www.mma.gov.br/estruturas/253/ publicacao/253 publicacao02022012 041757.pdf>. Acesso em: 05 jul. 2020.

BRASIL. Decreto 10.240 de 12 de fevereiro de 2020. Regulamenta o inciso VI do caput do art. 33 e o art. 56 da Lei no 12.305, de 2 de agosto de 2010, e complementa o Decreto o 9.177, de 23 de outubro de 2017, quanto à implementação de sistema de logística reversa de produtos eletroeletrônicos e seus componentes de uso doméstico.2020. Disponível em: $<$ http://www.planalto.gov.br/ccivil 03/ Ato2019-

2022/2020/Decreto/D10240.htm>. Acesso em: 04 jul. 2020.

BRASIL. Ministério do Meio Ambiente. Logística reversa deve aumentar de 70 para mais de $\mathbf{5}$ mil pontos de coleta de lixo eletroeletrônico no país. Brasília, fev. 2020. Disponível em: <https://mma.gov.br/informma/item/15702log\%C3\%ADstica-reversa-deve-aumentar-de-70-para-mais-de-5-mil-pontos-decoleta-de-lixo-eletroeletr\%C3\%B4nico-no-pa\%C3\%ADs.html> Acesso em: 13 abr. 2020.

BRASIL. Ministério do Meio Ambiente. Descarte de eletroeletrônicos. Brasília, fev. 2020. Disponível em: $<$ https://mma.gov.br/component/k2/item/15710-descarte-de-

eletroeletr\%C3\%B4nicos.html>. Acesso em: 13 abr. 2020. 
BRASIL. Secretaria de Governo da Presidência da República. Objetivos de Desenvolvimento Sustentável: ODS 12 - Consumo e Produção Responsável. 2019. Disponível em: <http://www4.planalto.gov.br/ods/objetivosde-desenvolvimento-sustentavel/12-consumo-e-producao-responsavel/12consumo-e-producao-responsavel>. Acesso em: 09 dez. 2020.

CARVALHO, I.C. de M. O sujeito ecológico: a formação de novas identidades na escola. In: PERNAMBUCO, M.; PAIVA, I. (Org.). Práticas coletivas na escola. 1ed.Campinas: Mercado de Letras, 2013, v. 1, p. 115-124.

IBGE - INSTITUTO BRASILEIRO DE GEOGRAFIA E ESTATÍSTICA. Cidades e Estados: Urussanga. Rio de Janeiro: IBGE, 2020. Disponível em: $<$ https://www.ibge.gov.br/cidades-e-estados/sc/urussanga.html>. Acesso em: 15 nov. 2020.

KIDDEE, P.; NAIDU, R.; WONG, M.H. Electronicwaste management approaches: An overview. Waste Management, n. 33, p. 1237-1250, 2013.

KITAJIMA, L. F. W.; GUARDA, G. F.; DALSTON, R. C. R.; BARCELOS, B. R.; DE MOURA CUNHA, G. H.; FERNEDA, E. A Educação Ambiental como instrumento na administração dos problemas do lixo eletrônico: uma proposta. Revista Brasileira de Educação Ambiental, v.14, n.3, pp.122-137, 2019.

MACEDO, M.F.S.; CAPANO, E.F. Política Educacional de descarte do lixo eletrônico como medida de combate ao crime ambiental. Revista Jurídica Cesumar. maio/agosto, v. 17, n. 2, p. 431-464. 2017.

NICOLESCU, B. O Manifesto da Transdisciplinaridade. Triom: São Paulo, 1999.

Disponível

em:

$<$ https://edisciplinas.usp.br/pluginfile.php/4144517/mod resource/content/0/O\%

20Manifesto\%20da\%20Transdisciplinaridade.pdf > Acesso em: 18 mai. 2021.

ONU. Gestión Sostenible de residuos de aparatos eléctricos y electrónicos em América Latina. 2015. Disponível em: <https://www.itu.int/dms pub/itu-t/oth/0b/11/T0B110000273301PDFS.pdf>

Acesso em 13 abr. 2020.

OTERO; P. B. G.; NEIMAN, Z. Avanços e desafios da Educação Ambiental Brasileira entre a rio92 e a Rio+20. Revista Brasileira de Educação Ambiental, São Paulo. v.10, n.1, p.20-41, 2015.

PREFEITURA pode recolher apenas lixo domiciliar em Urussanga. Município de Urussanga. $2015 . \quad$ Disponível em: $<$ https://www.urussanga.sc.gov.br/noticias/index/ver/codMapaltem/6335/codNot icia/272998 >. Acesso em: 17 abr. 2020.

RESÍDUOS ESPECIAIS. Cirsures: Consórcio Intermunicipal de Resíduos Sólidos Urbanos da Região Sul, 2020. Disponível em: $<$ http://www.cirsures.sc.gov.br/coleta-seletiva/residuos-especiais >. Acesso em: 27 jun. 2020. 
ROA, K.R.V., et al. Pilhas e baterias: usos e descartes $\mathbf{x}$ impactos ambientais. Caderno do professor. GEPEQ- USP: curso de formação continuada de professores, 2009. Disponível em: $<$ https://silo.tips/download/pilhas-e-baterias-usos-e-descartes-x-impactosambientais-caderno-do-professor>Acesso em: 24 mar. 2020.

SALES, E.S. et al. O lixo eletrônico e as suas potencialidades: um estudo das teses e dissertações nos últimos 3 anos. In: 60 Fórum Internacional ECOINOVAR, 2017, Santa Maria/RS, Anais. Santa Maria/RS: Ecoinovar, 2017, p.1-11. Disponível em: $<$ http://ecoinovar.com.br/cd2017/arquivos/artigos/ECO1531.pdf>. Acesso em: 27 jun. 2020.

SCHARF, R. Baterias velhas voltam às fábricas. Gazeta Mercantil, São Paulo, 13 mar.2000. Caderno Nacional, p.A-10.

VILELA, P.R. Decreto obriga empresas a recolherem lixo eletrônico. Agência Brasil, 2020.2 Disponível em: $<$ https://agenciabrasil.ebc.com.br/politica/noticia/2020-02/decreto-obrigaempresas-recolherem-lixo-eletronico> Acesso em: 04 jul. 2020.

SILVA, M.W.X.; SANTOS, E.A. dos; JESUS, C.V. Avanços e desafios na Educação Ambiental após a Conferência Rio+20: uma revisão da literatura. Disponível em: $<$ http://engemausp.submissao.com.br/20/anais/arquivos/359.pdf> Acesso em: 22 out. 2020.

WIDMER, R.; OSWALD-KRAPF, H.; SINHA-KHETRIWAL, D.; SCHNELLMANN, M.; BÖNI, $H$. Global perspectives on e-waste. Environmental Impact Assessment Review, n.25, p. 436-458, 2005. 